\title{
How are Iranian Gay Men Coping with Systematic Suppression Under Islamic Law? A Qualitative Study
}

\section{Mohammadrasool Yadegarfard ${ }^{1}[$ ]}

Published online: 20 May 2019

(c) The Author(s) 2019

\begin{abstract}
The existence of gay men is undeniable in Iran; however, Iran's Islamic law considers same sex relationships a crime punishable by the death penalty. The aim of this study is to use a qualitative approach to gain a more in-depth understanding of the coping strategies adopted by gay men living in Iran under systematic suppression based on each individual's subjective experiences, feelings, intention and beliefs. A semi-structured interview in Farsi (Persian) language was used to gather the qualitative data. Twenty-three men who identified themselves as gay and who currently live in Iran were interviewed for this study. Transcripts of the interviews were subjected to analysis using thematic analysis. The key themes that emerged as coping strategies were: risk taking; internalized oppression; travelling/leaving the country; social networks and family of choice; mental health and psychological therapy and medication; social class; and developing a new identity. The implications of these findings are discussed.
\end{abstract}

Keywords Gay culture · Gay men · Iran (Islamic Republic of) · Systematic suppression · Thematic analysis · Qualitative research

\section{Introduction}

Matsumoto and Juang (2017) observed that a group of people living in an isolated location under certain environmental conditions will adapt by developing survival techniques which contribute to the formulation of a new society. This new society will comprise its own beliefs and code of conduct as it evolves to form a unique culture. One example of such a society is the gay community in Iran, which has established its own behaviours and beliefs. LGBT individuals in Iran have been suffering from systematic suppression and discrimination for decades and, in order for them

Mohammadrasool Yadegarfard

mohammadrasool.yadegarfard@study.beds.ac.uk; mohammadrasool.yadegarfard@gmail.com

1 School of Psychology, University of Bedfordshire, Luton Campus, University Square,

Luton LU1 3JU, UK 
to survive, like any other minorities and isolated groups, they have formed a unique culture.

While some may consider homosexuality to be a relatively new Western phenomenon, a brief look at the history of same-sex relationships in Iran reveals that it is, in fact, prevalent throughout Iran's historical culture. Indeed, studies by both Western and Iranian scholars have shown that homosexuality has played a role in Iranian culture for millennia (Shamisa 2002; "Homosexuality iii" 2012; Parnian 2006). Despite this long history of homosexuality in Iran, many of the country's current homosexuals, particularly the younger generation, tend to identify more with a modern perspective rather than a historical or even cultural one (Mahdavi 2012; Yadegarfard and Bahramabadian 2014). At the same time, Iran's Islamic law considers same-sex relationships a crime punishable by the death penalty (Iran: Islamic Penal Code 1991). In such an oppressive environment, there is a lack of official information on Iran's homosexual population (Human Rights Watch 2010). However, it has been reported that somewhere in the range of 4000-6000 Iranians, both male and females, have been executed since 1979 for engaging in same-sex relationships based on estimations provided by human rights activists and opponents of the strict Iranian regime (UK Home office 2016).

Iran has also attracted global attention for the high number of sex reassignment surgeries carried out there (Human Rights Watch 2010). However, a significant number of those who undergo the surgery do so not because they are transgender but because they are gay, lesbian or bisexual and see sex change surgery as the only option for them to "erase the 'stain' of homosexuality and become 'legal' under Iranian law" (Human Rights Watch 2010, p. 3). Indeed, reports indicate that almost half $(45 \%)$ of all sex reassignment surgeries performed in Iran are carried out as a 'cure' for homosexual men or lesbians (Hamedani 2014). Unsurprisingly, not only does this approach fail to 'cure' the condition, but it also leads to increased depression, social anxiety, identity crises, self-harm, and suicide for those forced or coerced into such a dramatic action (Greene 2010; Davies and Neal 2003). Human Rights Watch has expressed its concern over this issue by urging the Iranian authorities to change their policy of supporting sex reassignment surgery as a means of making sexual minorities 'legal' under Iranian law (Human Rights Watch 2010). The practice of applying sex reassignment surgery as a 'cure' for sexual minorities in Iran has its roots in the country's strictly Islamic traditional cultural norms which consider gender to be a binary concept with no exceptions (Ikrami 2013; Justice for Iran 2014). Backed by state law, this belief has resulted in the formulation of a normative binary framework of attitudes, behaviours and actions which excludes all those who do not conform, including gay males (Justice for Iran 2014). While a major factor in this issue is how the Iranian authorities' policy and law have created an environment of social isolation, it is further compounded by professional practitioners and psychologists in Iran and their attempts at 'treating' the sexual 'deviancy' of homosexuals and lesbians (see Amin 2015). It is pointed out by Yadegarfard and Bahramabadian (2014) that confused diagnoses, unethical practice among professional practitioners in Iran result from the lack of a clear codes of conduct related to sexual orientation and gender identity and the shortage of local studies about Iranian sexual minorities. The reasons why researchers have largely avoided studying sexual minorities and 
gender identity in Iran are attributed to certain conditions in the country, such as religious perspectives and laws, cultural biases, misunderstandings, a lack of local academic and scientific resources, and Western conspiracy theories (Yadegarfard and Bahramabadian 2014). Therefore, the aim of this study is to use a qualitative approach to gain a more in-depth understanding of gay men living in Iran under systematic suppression. This understanding will be based on each individual's subjective experiences, feelings, intention and beliefs. A general research question for this study, therefore, is: how are gay men coping with systematic suppression in Iran?

\section{Methodology}

\section{Interview}

A semi-structured interview in Farsi (Persian) language was used to gather the qualitative data. The semi-structured interview provided more flexibility for the participants to explain and elaborate their answers, which helped the researcher to gather more information and better understand how the participants perceived and made sense of their coping strategies under an environment of systematic oppression. An example of an open-ended question included in the interview schedule is 'What is a gay man's life like in Iran?' The interview schedule was structured into the following five sections: Family Background and Relationship; Sexual Identity; Sexual Relationship; Social Life and Social Network; and Coping Strategies with Islamic Law.

\section{Sampling, Data Collection and Ethical Consideration}

As gay individuals are a difficult-to-find group (hidden group) in Iran, the researcher required the assistance of relevant organisations. While there are no dedicated LGB organisations in Iran, many LGB individuals receive sexual health support (such as HIV testing) through Non-Governmental Organizations (NGO). The researcher then contacted these organizations and explained the objectives of the research to the directors in order to seek their permission to conduct the study. The criteria for the sample were male individuals who identify themselves as male, man and gay, age 18 and above who permanently live in Iran. Few participant approached the researcher through these organizations. Then through snowball sampling 57 gay men were contacted through email and only 38 people replied to the initial email, then inform consent were sent to 38 prospective participants that of them only 29 showed interest to participate in the study, the rest dropped out due to the sensitivity of the subject, fear of discloser, fear of dealing with stress during the interview, not knowing the interviewer and lack of trust and not feeling comfortable to do the interview trough video call. From the 29 confirmed participants only 23 individuals turned up for the interview.

As already mentioned, all participants were sent an informed consent form via email before the meeting was arranged so that by the time of the interview, they 
were all aware of the topic, aim, and objective of the study. The prospective participants who were in their twenties seemed to be more open about their sexuality and less cautious about disclosure and confidentiality and therefore more willing to participate in the study; one explanation for this is that the younger generation are less accepting of the authority's religious and political views, while access to the internet and social media has provided them with the freedom to express their sexual identity more comfortably (see Mahdavi 2012). However, the participants who were in their mid-thirties and above seemed to be more discreet, more cautious about confidentiality, and less able to trust the researcher. At the same time, however, they expressed their willingness to participate because they felt any research of Iranian gay men might contribute to the development of knowledge and understanding of gay men and their current situation in Iran. Indeed, some of the main reasons given by participants for agreeing to participate in the current research were that, through this research, the authorities might hear their voice saying "we exist"; they were fighting stigmatisation and discrimination; and they were raising awareness in society about gay men in Iran. In addition, the researcher's position as a bilingual (fluent in both Farsi and English) and qualified psychologist with a long experience of working with LGBT individuals helped the sampling process by facilitating the development of a rapport with the participants.

As the researcher does not currently live in Iran, the only option was to conduct the interviews online (via Skype, Facebook video call, Instagram and WhatsApp). Discussing the advantages and disadvantages of online interviewing is beyond the scope of this article (see Janghorban et al. 2014; Nehls et al. 2015). Nevertheless, online interviewing helped the researcher to overcome the geographic limitations of this study, while it also enabled the interviewees who had time limitations to participate in the research as the interviews could take place under conditions that were more convenient for the participants. In addition, participating in an online interview gave the participants the right and the control to be seen or not to be seen by the interviewer or to withdraw from the interview process at any point just by clicking a button. Discussing all the ethical aspects and dilemmas faced by the researcher during this research is also beyond the scope of this current article, and this is an issue that perhaps needs to be explored as an independent article. Nevertheless, the ethical issues that apply in online interviewing are considered the same as those in face-to-face interviews (Nehls et al. 2015). There are two main ethical dilemmas for consideration in the current study. Firstly, although the researcher explained the aim and objective of the research in the informed consent form, some of the participants enquired further about the purpose of the study at the outset of the interview, obliging the researcher to give the participants additional explanations, which consequently helped to develop a rapport and trust throughout the interviews. However, it has been pointed out that the extent to which a researcher reveals the actual purpose of the study could influence the amount of information that participants share with researcher, which might consequently affect the validity of the data (Merriam and Tisdell 2016).

Secondly, some of the interviews turned to be more like a therapy sessions. This is perhaps because during the introduction to some of the interviews, the researcher disclosed his profession as psychological therapist. However, to overcome this 
dilemma, the researcher then reminded the participants about the nature of the interview and its aim and objective. Nevertheless, for two participants, the researcher had to make decisions based on the situation (Situated ethic or situation ethics recommended by Taylor 2017; Simons and Usher 2000) and allowed these particular interviews to be more reflective and therapeutic for the participants as it would have been unethical of the interviewer to leave these two particular participants in distress due to the interview. Under relational ethics, importance is placed on the researcher being aware of his or her own role, understanding how he or she may affect the relationship with the study's participants, and ensuring the study's participants are treated as human beings rather than just sources of knowledge to be mined (Tracy 2010). Also, it is reported that in Iran, many LGBT individuals have found it difficult finding a trusted psychological service as there is no official trained therapist working with LGBT individuals in the country (Yadegarfard et al. 2015). However, at the end of the interviews, the researcher provided the participants with some information regarding the most relevant sexual health charity organisations in Iran.

It is worth noting at this point that neither the participants nor their demographic characteristics were known by the researcher prior to the study. While it was the researcher's intention to study only non-vulnerable adults, the snowball sampling technique provides a degree of ambiguity over who is selected for participation, in spite of the researcher's screening process. The researcher, therefore, felt it necessary to include certain safeguards to prevent those participating in the qualitative research interviews from being exposed to any harmful effects arising from their participation (British Psychological Society 2014). For this very reason, it is recommended that researchers design interview questions which "ensure[s] that the physical, social and psychological well-being of research participants is not adversely affected" (British Psychological Society 2014, p. 2). Despite this, the difficulty in clearly defining let alone guaranteeing "well-being" is well understood (Hollway and Jefferson 2013). Indeed, even the concept of "safeguarding" is far from clear in either its definitions or its practice. In the present study, safeguarding the participants involved verbal reassurances from the researcher, assuring the participants that they had full access to the support systems that had been purposefully established in the event that they suffered distress either during or after the interview. In addition, the researcher was fully aware that asking questions about their personal life might cause distress for some of the participants. Consequently, to tackle this issue, the researcher provided sufficient explanation and acknowledgment before the interview. Furthermore, the participants were made aware through the informed consent form that they could withdraw their participation at any time or they could contact the researcher after the interview if they decided that they did not want their data to be used in the study.

Since the author of this present study is an independent researcher, it was decided that three professors of social psychology who are experienced independent chartered psychologists would be selected to review the submitted research proposal. The researchers also handled all collected data in strict accordance with the code of human research ethics (British Psychological Society 2014). Finally, assurances were given to all participants regarding their anonymity and the confidentiality of their personal information. 


\section{Participants}

Twenty-three men who identified themselves as gay and who currently live in Iran were interviewed for this study. In terms of the participants' ethnicity, all of them reported that they were Iranian. The participants' ages ranged from 19 to 52 years (Table 1).

\section{Data Analysis}

In addition to using thematic analysis (Braun and Clarke 2013) in this study, the researcher also used NVivo (data analysis software) for analysing the qualitative data. In identifying the themes, the analysis also employed a semantic approach by focusing on the data's most obvious or superficial interpretations (Braun and Clarke 2013). Data analysis was accomplished through the following statistical treatments: transcription, organisation of the data, familiarisation, coding, themes and verification.

Table 1 Participants demographic information

\begin{tabular}{|c|c|c|c|c|}
\hline $\begin{array}{l}\text { Participant } \\
\text { number }\end{array}$ & Age & Relationship status & Employment status & Education \\
\hline 1. & 36 & Single and dating & Employed & High school \\
\hline 2. & 28 & Cohabitation & Unemployed & Graduate \\
\hline 3. & 52 & Single and dating & Self-employed & High school \\
\hline 4. & 41 & In a relationship & Self-employed & Undergraduate \\
\hline 5. & 20 & Single and dating & Student & Undergraduate \\
\hline 6. & 25 & In a relationship & Unemployed & Undergraduate \\
\hline 7. & 22 & Single and dating & Unemployed & High school \\
\hline 8. & 27 & Cohabitation & Employed & Undergraduate \\
\hline 9. & 43 & Single and dating & Employed & Post-graduate \\
\hline 10. & 21 & Single and dating & Student & Undergraduate \\
\hline 11. & 28 & Single and not dating & Unemployed & Undergraduate \\
\hline 12. & 35 & In a relationship & Self-employed & Post-graduate \\
\hline 13. & 46 & Single and dating & Unemployed & High school \\
\hline 14. & 19 & Single and dating & Student & High school \\
\hline 15. & 30 & Single and not dating & Unemployed & Post-graduate \\
\hline 16. & 21 & Single & Student & High school \\
\hline 17. & 49 & In a relationship & Unemployed & High school \\
\hline 18. & 32 & In a relationship & Self-employed & Undergraduate \\
\hline 19. & 22 & Single and dating & Student & High school \\
\hline 20. & 27 & Single and dating & Student/part-time & Undergraduate \\
\hline 21. & 23 & In a relationship & Student & High school \\
\hline 22. & 40 & Single and dating & Employed & Post-graduate \\
\hline 23. & 37 & Single and dating & Employed & High school \\
\hline
\end{tabular}


In this study, the material was coded in line with the principles outlined by Braun and Clarke (2013). The data were coded through an integrated approach which utilised both deductive and inductive reasoning, meaning that the data were gathered not only from the respondents but also from the theoretical understandings of the researcher (Braun and Clarke 2013). During the first round of coding, sixty-five codes were identified by the researcher. In the next round, the codes were grouped according to the similarity of their content. This pattern was repeated until only seven main 'themes' remained. After the coding was completed, seven themes were identified, each defining ways in which the candidates described their adjustment.

Listening to some of the interviews during the transcription process was very emotional for the researcher, especially concerning some of the participants' traumatic experiences of prison, humiliation, and abuse in public by the morality police because of their sexuality. Indeed, many researchers have pointed out just how emotional it can be for a transcriber working on research interviews when the topic is particularly sensitive. As they are exposed to the often harrowing accounts of the study's participants, the transcribers are vulnerable to "absorbing" the intense nature of those events (Warr 2004). Nevertheless, the researcher was aware that being emotionally sensitive could prejudice his judgment and consequently lead to a misinterpretation of the data. Therefore, to mitigate the emotional exposure of the transcribing process, the researcher took frequent breaks; he also benefited from supervision during the process of research.

As the participants were Iranian with Farsi as their main language, and also as the researcher is bilingual, being fluent in both Farsi and English, the interviews, transcriptions, coding and themes were all done in Farsi. There are two main advantages of completing these four stages in the original language. Firstly, it helped to prevent any potential limitations in the analysis (Recommended by van Nes et al. 2010), and secondly the findings needed to be in Farsi, as part of the verification process had to be sent to the original participants in order for them to check whether their viewpoints had been represented correctly and accurately. However, only ten of the participants showed interest in this and participated in the post checking. They all confirmed that the factors mentioned in the findings were either coping strategies or ways of living in Iran. There were no objections about any of the factors mentioned in the findings. After the researcher gained the verification of the findings by some of the participants, the researcher translated them into English. Even though the researcher is bilingual and well aware of both the original and target language, to increase the validity and accuracy of the data analysis and of the translation from Farsi to English, two professional translators were involved in the process (Recommended by van Nes et al. 2010). One of the translators was also a social psychologist and experienced in conducting qualitative research.

\section{Findings and Discussion}

Based on the results of the data analysis, the key themes that emerged as coping strategies were risk taking; internalised oppression; travelling/leaving the country; social network and family of choice; mental health and psychological therapy and medication; social class; and developing a new identity. 


\section{Risk Taking}

One of the main themes that was identified was risk taking. Risk taking manifested itself in all behaviours that had the potential to put the person in a vulnerable position, whether physically, mentally or socially. It seems that when engaging in such an activity, all of the participants were aware of the risk and the consequences of such action but still committed to it. The acts of risk taking that were identified in this study were sexual activity, gathering in public and underground get-togethers or parties, substance misuse, and cross dressing in public.

Thirteen participants mentioned that despite all the restrictions and limitations, even though same-sex relationships are condemned as a crime that carries the death penalty, one thing that helps gay people to "cope" was having sex. Three main reasons were given by the participants for why they take the risk and engage in sexual relationships. Firstly, having sex is an act of rebellion and non-conformity. Secondly, sex gives them a sense of identity and of who they are. Thirdly, sex helps them to connect to other gay men and engage in social networking as a coping strategy for social isolation and loneliness.

The narrations of the participants' sex experiences were very varied; for instance, two participants mentioned that because they had their own home, they could have sex 3-4 times a week. They reported that their sex partners were found from social media or dating apps, or they even sometimes found their sex partners from public places such as parks. Other participants mentioned that as they travelled to different cities, they had more opportunities to meet new people and have more sex. Two participants also mentioned that they had sexual intercourse even if they did not have protection. One of the participants explained:

...sometimes you get caught up in a situation where you don't have any protection with you; on the other hand, you don't want to lose your opportunity, so you just go for it. You have to trust.

Participant 7

It has been shown that individuals with less social support are more likely to commit risky sexual behaviour (e.g. Johanston et al. 2017; Saleh et al. 2016; Choudhury et al. 2015; Yadegarfard et al. 2014; Glick and Golden 2014; Kapadia et al. 2013; Majumdar 2006). There is a school of thought which suggests that the practice of engaging in risky sexual behaviour serves as a symbolic act of rebellion by gay males, albeit one that may be carried out subconsciously or even just as part of the accepted gay culture (Crossley 2004). Psychologically, the act of engaging in risky sexual practices may provide some members of the gay community with a fulfilling sense of protesting and rebelling against the dominant social values which they feel oppress their freedom and independence (Crossley 2004).

In addition, two participants mentioned that they even stood in the street, especially in the evening and at nights, to get picked up by cars. They mentioned there were well-know "pick-up points" in Tehran for gay men such as zeer-e-pole karim khan (under the Karim Khan bridge). They both clarified that they were not sexworkers and it was not even necessary for them to have sex when they were picked up. One of them explained that: 
Gays like me are not active on social media, and as there is no place for us to hang around, we go and stand under Karim Khan bridge (Zire pole karm khan). They call us "Khanoom ghadimi" (traditional ladies). We know we might get caught up with the police or the Basiji but what other option do we have? Sometimes I do it with "other ladies" ("khanoomaye dige" refers to other gay guys)... It's fun.

Participant 23

There are many reports of gay individuals standing in the well-known "pick-up points" who have been beaten to death by strangers or even by the morality police or the Basij (UK Home Office 2016).

The most common risk taking act identified was "gathering in public and underground get-togethers or parties". All twenty-three participants mentioned that they attended private gatherings and parties (Mehmooni) as well as gatherings in public places such as parks and restaurants. All of the participants also stated that there was always risk when attending these kind of gathering and parties. Three participants mentioned that they had experience of being arrested by the police at one of the parties. For instance, participants 1, who was 36 years old, single, and employed, said:

We were at a party..., the police came and arrested everyone. We had alcohol and everything. Some of us were at the prison for three weeks. They treated us like criminals.

Participant 1

These examples concur with numerous reported cases of homosexuals in Iran being arrested for attending parties, punished with fines, and also warned that they faced execution if caught a second time (Forbes 2017). A total of 230 people were arrested by Iran's morality police in 2017 following raids on two parties in Tehran (BBC News 2017). Despite all these restrictions and punishments, it seems that gay individuals do not stop attending underground parties. As participant 10, who was 21 years old, single, and a student, said:

It has always been like this after the revolution. They arrest us, charge us and imprison us, but they don't know it does not stop us at all....

Participant 10

Four reasons were mentioned by the participants for why they take the risk and attend public gathering or underground parties. Firstly, it is an act of rebellion and non-conformity. Secondly, getting together gives them a sense of belonging and identity and, thirdly, it connects them to other gay men and facilitates social networking, which is a coping strategy for dealing with social isolation and loneliness. Finally, it gives them an opportunity to find a sex partner.

Despite the dangers, it is still fairly common for gay males in Iran to arrange underground house parties where alcohol is consumed. They mitigate the danger by only inviting people they know. There is also a reliance on the old Persian adage: "Whatever goes on between four walls, stays between those walls". While these parties feature illegal activities, such as same-sex relationships, the consumption of alcohol, and drug abuse, they are done so in a non-public environment. The morality 
police and Basij (The Organisation for the Mobilisation of the Oppressed) mostly arrest people for committing "un-Islamic" offences in public places, especially in summer when people spend more time outside (Human Rights Watch 2010). Even so, some of the participants in this study mentioned that it can be safer for them to gather in public places as they can often escape quickly if the police arrive. This has been the norm in Iran since the Islamic revolution of 1979 with members of the morality police patrolling public places regularly (Golkar 2010).

The second most common risk taking identified was substance misuse. Twelve out of twenty-three participants mentioned that they had experience of substance misuse. Both illegal drugs, such as recreational drugs (ecstasy) and marijuana (weed, grass), and prescribed drugs, such as Tramadol, were mentioned by the participants. However, alcohol was the most common substance used by the participants. As participant 6, who was 25 years old, in a relationship, and unemployed, said:

Alcohol is always available in our parties. It relaxes you, you know. Some people drink more than others. You have to be careful though, because they (the host) might be serving you all sorts of crap.

Participant 6

There are two types of risks related to alcohol in Iran. Firstly, selling, buying and consuming alcohol is illegal and individuals can be charged with imprisonment or public lashes. In fact, most of the arrests relating to homosexuality in Iran are made in raids on private house parties. The raids are usually carried out under the justification that alcohol is being consumed illegally, as well as other acts in contradiction of Islamic law, such as dress code violations and "debauchery" (UK Home office 2016). Secondly, there is a health-related risk. As alcohol is illegal in Iran, many people use home-made hooch, which can cause serious physical harm and even death. Due to the drastic decrease in the value of the Iranian currency against the US dollar recently, there is an increased likelihood that Iranians are opting for cheap homemade alcohol rather than expensive foreign imports. This brings with it a serious risk of illness and even death due to the unregulated nature of the alcohol production. As recently as October 2018, 460 people were hospitalised in Iran after consuming homemade alcohol, and at least 42 of these cases proved fatal (BBC News 2018). In spite of the legal and health-related risks associated with alcohol and drug use in Iran, gay men are still misusing these substances as part of their coping mechanism for dealing with the stress and anxiety caused by their social isolation, discrimination and systematic suppression.

It has been observed that many members of the gay population use alcohol and drugs to overcome the pain of rejection, isolation, and discrimination (e.g. Varney 2016; Wolitski et al. 2008). Although, because of all the restrictions, alcohol usage in Iran is significantly lower than in many other countries (World Health Organization 2014), the use of opium and opium residue is much higher in Iran. In fact, Iran is currently ranked second in the world for severe addiction to opioids (Zarghami 2015). The Iranian Drug Control Headquarters estimated that, in 2015, as many as 2.8 million Iranians aged 15-64 years old were addicted to illicit drugs. It was also found that most addicts began using opioids in their early $20 \mathrm{~s}$ and the average age of addicts was 32 years old. Even though addiction to opioids is often associated 
with biopsychosocial factors, it was also found that drug use is common among all social classes in Iran. One reason for this appears to be the positive traditional attitude towards raw opium use (Zarghami 2015). Nevertheless, there is no known study of substance misuse among gay men living in Iran. As a result, more research needs to be carried out in this area.

Cross dressing in public was another form of risk taking. Three clients mentioned that to cope with the family and social pressures and even to deal with identity confusion, they used to cross dress as women in public. Two of them stated that twice they had been arrested by the morality police or the Basij. However, it did not stop them from doing the same again. They mentioned that they did not consider themselves to be transgender and cross dressing was just a way of expressing their difference to others. They mentioned that they were aware of the risk that they were taking but it was the only way that could express their feelings. As participant 18, who was 32 years old, in a relationship, and self-employed, mentioned that:

...I did not know I was gay when I was 19 and I did not know any other gay man, but I knew I was different from other men in my family and at the school, so cross dressing helped me to navigate my feelings and my identity.

Participant 18

One important observation is that life is easier for transgender women in Iran than it is for gay males. This can perhaps be explained in a cultural context where a gay man appearing as a woman is considered less morally wrong in a patriarchal binary society such as Iran (Banning-Lover 2017). The state also acknowledges and recognises transgender individuals as having a medical condition. Unlike for the gay male population or other sexual minorities, there are a number of trans-focused NGOs in Iran and this has helped boost the confidence levels of this group (Human Rights Watch 2010). Even so, instances of supplice in the form of whipping are still a fairly common punishment for members of sexual minorities who dress inappropriately (Forbes 2017). It seems that wearing clothes which challenge stereotypical notions of femininity and masculinity place those who practice such acts at risk of arbitrary arrest, detention, and ill-treatment.

\section{Internalised Oppression}

Internalised oppression was another theme that was identified in the interviews. Internalised oppression is the situation in which a particular group of people feel that they are regarded as being of lower value than another group of people, such as those who are considered "normal", leading the internally oppressed group to wish that they could be more like the other group with the perceived higher value (Mason 1990). This form of oppression can manifest itself in members of marginalised groups having oppressive views toward their own group, or even beginning to affirm the negative stereotypes of their group (David and Dethrick 2014). For instance, participant 15, who was 30 years old, single and not dating, and unemployed, mentioned that although he knew that he had no sexual or emotional desire towards the opposite sex and he was sure that he was gay, he did not follow 
his desire. Instead he practiced his religious belief and had completely left his sexual desire out of the equation. He said at first it was difficult to do it but now after a year he had got used to it.

I don't know how long I can carry on like this but for now, it seems to be working...it is a spiritual journey and I know that not everyone understands it.

Participant 15

Also, three other participants mentioned that they had similar experience, as they always felt ashamed and guilty about being gay, so to compensate, they started practising their religion more seriously. However, after a period of time, they found that their sexual desire was natural and it was nothing to do with whether they practiced their religion or not. Eleven participants mentioned that they found it challenging believing in Islam and being gay simultaneously; five participants also mentioned that they had left their religion and they now considered themselves as atheists.

As Iran is an Islamic country and religious education is mandatory for everyone at school from a very early age, hypothetically it might have some level of impact on an individual's sexual behaviours in general. Research has shown that making efforts to 'change' one's sexual identity through religious activities, such as engaging in personal righteousness through, for example, prayer, fasting, studying the Quran, or seeking to improve one's relationship with Allah; receiving counselling from religious leaders, such as an Imam or Sheykh; or practicing individual methods, such as introspection, private study, or mental suppression, are far more common than receiving 'treatment' from a therapist or participating in group-led efforts, but also far more damaging. One study carried out by Dehlin (2015) among 1612 same-sex-attracted Mormons revealed that $0 \%$ of those attempting to change their sexuality reported any success in eliminating their attraction to members of the same sex. Making efforts to change one's sexuality have also been shown to be either ineffective or damaging. Aside from damaging the individual's confidence and mental well-being, such efforts can also create conflict between their sexual and religious identity, leading to them rejecting their religious identity altogether (Dehlin 2015).

In addition, four participants commented that at various points in their lives (during their early $20 \mathrm{~s}$ ), they had undergone the conversion therapy introduced by some psychiatrics and psychologists. All four of the participants mentioned that it had been unsuccessful, and they even suffered more from depression and anxiety afterwards, while participant number 12 , who was 35 , in a relationship, and selfemployed, mentioned that it pushed him towards self-harm and suicidal thinking.

It was a horrible experience. I swear to god that the psychologist did not know shit about homosexuality. She just didn't. My family forced me to do it. All that time and money. I got worse, depression, anxiety, and at the end, even my family blamed me that I didn't want to change. Blamed me! Can you believe it? I really wished I was dead.

Participant 12

A report released by Human Rights Watch in 2010 stated that hundreds of Iran's LGBT community had received counselling, diagnosis and even 
"treatment" for their "sexual deviancy" from numerous prominent psychologists, sexologists, and psychiatrists operating with the tacit approval of the state (Human Rights Watch 2010). Supporting this strategy, Cohanzad (2012) claimed that homosexuality could be treatable by psychotherapy. As another example, Yasami et al. (2007) reported how they adopted various methods of cognitive behaviour therapy (CBT) such as covert aversion (aversion therapy, using electro shock and vomit-inducing drugs) to successfully "treat" three homosexual and two transsexual "patients", who exhibited heterosexual behaviour after receiving the therapy. In this study, it was observed by the researcher that the reason for the success of the treatment was largely due to the patients' desire to change because of their understanding that homosexuality or transgenderism was unacceptable in Iranian culture.

Moreover, three of the participants had married members of the opposite sex, with one participant even going so far as to marry three times with three different women before divorcing each one of them, although not before producing four children from those marriages. These three participants mentioned that a traditional marriage was a way in which they could cope with family and social pressures and stress. A report by the Home Office in the UK stated that there was a major issue of gay individuals reporting various forms of abuse from members of their own family in response to their sexual orientation and gender identity. The mental and sometimes physical abuse was sometimes followed by the threat of an arranged marriage, which was even turned into a reality in some cases. As homosexuality is a crime in Iran, gay individuals have little hope of receiving justice or even support when they are subject to abuse or violence within their own families. In such an environment of persecution and neglect, many non-state actors carry out acts of homophobic violence with impunity (UK Home Office 2016).

Two of the three who had married mentioned that, even though they were married, they had relationships with other men in secret. They specifically mentioned that they had double lives, which made it extremely difficult both for them and for their wives. Of these three participants, only participant 13 who was 46, single and dating, and unemployed, mentioned that during his marriage, he never got involved with any other man. However, during this time, he mentioned that he suffered severely from depression, anxiety and OCD and he was heavily dependent on anti-depressants for four years. Nevertheless, after having therapy, he decided to get a divorce. He explained:

...the divorce was like I was born again. It opened my eyes really. It helped me to find out who I am; despite all the difficult situations I had to go through, it was totally worth it. ...for gay people, living in Iran is like living in prison, but being gay and getting married with a woman, with someone that you don't like, is like living in a cage inside a prison.

Participant 13

Iran's culture is rigidly patriarchal (Khosravi 2009). Inter-gender social interactions are defined and controlled, and dominated by masculinity. Men are automatically empowered as phallic owners of any non-masculine figure, not only in private but also in public. Iranian tradition dictates that men marry a girl for the purpose 
of continuing the discursive reproduction of social structures through procreation. A nuclear family in Iranian culture is defined as at least a married couple of one man and one woman, which aligns with the Western definition of sociologists such as Giddens and Griffiths (2006). In all definitions of family, the consistent roles of a man/father and woman/mother serve as a reminder of the dualistic approach employed by structuralists in the study of social institutions (Butler 2002). In particular Levi-Strauss (1969) highlighted the dualistic structure of man-woman as essential in recognising an institution as a family. It is suggested that the very social structure in which individuals live can be a stressor if its values are in contrast with, or inaccessible to, those individuals (Farley and Flota 2017; Giddens and Sutton 2017). In Iran, sexual minorities have been excluded from the norms and structures of the dominant culture, as exemplified by the lack of a same-sex marriage equivalent for gay and lesbian partners.

\section{Travelling/Leaving the Country}

Travelling more than usual was another coping strategy that was reported by the participants in this study. Three of the participants mentioned that dating and meeting other gay men in their home town was difficult, so they travelled to other cities. They explained that dating people in their home town would put them in a vulnerable position as their sex partners might find out where they lived and cause problems, or, as participant 22, who was 40 years old, single and dating, and employed, mentioned:

...you put yourself in a position where people can take advantage of you or even blackmail you.

Participant 22

Also, two participants mentioned that they were also worried about their own family seeing them hanging around with other gay males, especially if they were a bit "feminine" or "camp (Eva)". To avoid all these hassles and unnecessary complications in their home towns, they travelled to other cities three to four times a week, which they mentioned was both costly and time consuming. Nevertheless, they still they did it because it was the only way they could cope with their situation as gay men.

One participant mentioned that he was in a relationship and his partner was European, so he commuted between Iran and Europe. He mentioned that he could not leave the country for good as he had a very successful business in Iran. He mentioned it was an ideal situation for him as having a relationship with an Iranian gay in Iran always came with problems and consequences. He went on to mention that although it was costly, and distance was difficult, it seemed to be working for them.

Thirteen participants mentioned that they would leave the country and seek asylum in another country if they had the opportunity. Participant 3, who was 52 years old, single and dating, and self-employed, mentioned that he had been in Turkey for a year and claimed asylum but he had been struggling financially and had no support 
from the relevant organisation, so he came back. However, he was still thinking of leaving the country again. He continued that:

As a gay man, you can have everything and nothing here (in Iran). When you cannot be yourself, what's the point? You can have the best job, best car, best house but you cannot be yourself. You have to lie all the time, just not to get into any trouble.

Participant 3

The decision to relocate within the same country or migrate to another can be based either directly or indirectly on sexuality in terms of sexual identity, practices, and desires. The term "sexual migration" is, in fact, almost exclusively associated with the movement of homosexuals seeking sexual freedom with regard to their practices, identities, and subjectivities (Manalansan 2006). For Iran's gay male population, it is predominantly the country's Islamic law and society that drives them to migrate. The majority of Iran's homosexual refugees head to the neighbouring country of Turkey, where they can apply for asylum in the capital city of Ankara where the UNHCR's office is located. However, many find their time in Turkey is also stressful, filled with uncertainty, and lacking the support they expected to receive due to the conservative political environment that is only marginally better than that in Iran. The situation is made worse by the Turkish placement policy of concentrating homosexual refugees in small and often highly conservative cities (Saastamoinen 2017).

\section{Social Network and Family of Choice}

All of the participants mentioned that they either used to use social media and/or dating apps or were still using them. The main social media mentioned were Facebook, Instagram, Twitter, Telegram, WhatsApp, and Snapchat, while the most common dating apps mentioned by the participants were Grindr and Hornet. The main reasons for using social media according to the participants were connecting to other gay individuals, feeling that they were in a safe place, making conversation about homosexuality in Iran and LGBTQ rights, sex and finding a sex partner, looking for a more serious relationship, chatting with others which helped them regarding their isolation and loneliness, and also accessing information (see also Karimi 2016). Even though it was mentioned as a safe place, the Internet is also used by the morality police for the purpose of entrapment (Human Rights Watch 2010). Homosexual individuals who are rounded up during raids on gay parties are also often forced to become informants (Human Rights Watch 2010). The development of surveillance technology has made it easier to identify individuals who are interested in samesex relationships or who are looking for partners of the same sex. While the Internet helps people looking for homosexual partners by making them more visible to one another, it also has the downside of making them more visible to the repressive authorities.

Moreover, many of the participants mentioned that they created their own social network of people they could trust. Somehow, they created their own family of 
choice and kinship. For instance, participant 8, who was 27 years old, living with his partner, and employed, explained that:

One of the older gay guys who's financially stable, has his own dependency, has lots of experience with gay people, and can host people in his house usually becomes the head of our so called family. People get together around him. Some people might call him "mamman" (mother) or "malakeh" (The queen) or "amme bozorg" (great aunty), or other names which depend on the persons personality in this group of friends. Some call him big brother, sister, uncle, grand mom and so on and so forth.

Participant 8

Discussing the issue of the "family of choice" among gay men in Iran is beyond the scope of this research. However, it shows that gay men who have never been supported by their own biological family create a new and modern sense of family among themselves. This second family serves as a source of support and information as well as providing a sense of belonging which is imperative for gay individuals in a repressive society such as Iran. Also, it was mentioned that a gay couple who had been together for a long time became the source of emotional and social support for the mostly younger members of the gay group. In this new form of family, it seems that the person(s) who is usually in the centre tends to be someone who has a more secure and independent financial status. While the traditional definition of a family is an institution that is based on marital and biological ties, a "family of choice" is a union of relations that develop from kinship rather than marital and biological bonds with only a partial approximation to the traditionally understood family structure (Weston 1997).

\section{Psychological Therapy and Medication}

All of the participants reported that they had suffered from various forms of mental illness such as depression, anxiety, obsessive compulsive disorder (OCD), and selfharm. One of the participants also mentioned that he had attempted suicide. However only nine of the participants reported that they had ever used medication such as anti-depressants or received psychological therapy. They indicated how difficult it was for them to open up about their sexuality to practitioners, and so they mostly preferred to hide it.

One participant mentioned that to cope with his situation and the related stress at home, he used to isolate himself in his room watching porn and masturbating excessively. He would also spend hours on social media and chatting online with other people. It became so bad that he said there were times when he would not see his parents and siblings for days, even though they were in the same house. Participant 11 , who was 28 years old, single and not dating, and unemployed, commented that he had chosen intentional loneliness (solitude). He stated:

I have dedicated my life to volunteer jobs. I'm rarely home. I also go to the gym and camping every month and I'm also into music and play guitar. I'm 
super busy. I don't have time to think about sex, or dating people. I am happy on my own.

Participant 11

There is no official report regarding LGBT mental health status in Iran. However, a study conducted by an independent UK-based organisation found that $16.9 \%$ of its LGBTQ participants reported being "in a bad place" and suffering from mental health problems, while $30.9 \%$ reported they were just about coping but had problems with some mental health difficulties (Marchant 2018). In the same study, $64.6 \%$ of the participants reported that they had never spoken with a mental health professional about their sexual orientation or gender identity (Marchant 2018). There is no doubt that gay individuals in Iran experience 'minority stress', defined as a state resulting from "....culturally sanctioned, categorically ascribed inferior status, social prejudice and discrimination, the impact of these environmental forces on psychological well-being, and consequent readjustment or adaptation" (Brooks 1981, p. 107). Many researchers have shown that LGBT individuals typically experience a lower level of well-being than their heterosexual counterparts. In particular, LGBT individuals have been found to have higher levels of anxiety, depression and suicidal feelings than their heterosexual peers (NHS 2014). The reasons for the higher levels of depression, anxiety, and stress among LGBT populations has been at least partially attributed in various studies to social isolation, discrimination, suppression, and family rejection. As previously identified, there is then a tendency for gay individuals to turn to substances such as alcohol and drugs as a coping device to help them deal with their negative social experiences.

\section{Social Class}

The social classes of the participants in this study were very diverse. Just as with the general situation in Iran, a social class division was clearly evident among the participants as those with a higher social class tended to have more opportunities to cope with the social pressures regarding their sexual identity than participants from a lower social class. It is easier for individuals from a higher social class as they have a higher level of education or are more familiar with the concept of sexual orientation through travelling to Western countries, even if those who are religiously conservative. This situation can be seen in the narration of participant number 20, who was 27 years old, single and not dating, a student, and working part time. He said that:

... although my family are religious, because we go abroad (Western countries) a lot, they are familiar with the concepts (homosexuality). In my early $20 \mathrm{~s}$, I started travelling alone to Europe and other countries. I know I was lucky to be born in a, you can say, well-off family that could afford it, but not everyone does...

Participant 20

Participant 21, who was 23 years old, in a relationship, and student, mentioned that he was from a religiously conservative and wealthy family and his father was 
a politician. He told how his family had accidently found out about his sexuality. At first, his father used his power and forced him to go through therapy and to seek medical help, but after a period of time when he could see that medical and psychological interventions would not change anything, he gave up and decided to unwillingly give his son financial support. The participant commented:

... my father bought me a big house in the north of Tehran and a nice car and he also gives a me a handsome monthly allowance. He still does not speak to me properly, and I think he gave me all these things for me to shut up and not put his political position in trouble, which I don't mind. I have everything I need. I have my own life now...

Participant 21

Although the subjects of sexual self-expression and community involvement among minorities have been studied (e.g. Barrett and Pollack 2005), there is a lack of research into the specific issue of class bias. The obvious question that needs to be addressed is how an individual's social class and its associated resources would affect his ability to express his sexual orientation. The suggestion is that differences in social class result in different levels of access to the social, psychological, and economic resources that enable the individual to express his sexual orientation (Bowman 2004). The levels of acceptance of gays are consistently higher in urban and suburban areas and among those with a higher level of education or income (Whitcomb and Walinsky 2013; Bowman 2004). In addition, participant 4, who was 41 years old, in a relationship, and self-employed, mentioned that he was from a working-class family living in the south of Tehran and that the situation for gay men there was more difficult than for people in the north of Tehran, as people in the south were more traditional and conservative than people from the north. He stated that because of this, not many gay men from north Tehran hung around with gay men from the city's south.

...they don't usually hang around with "Khanoomha e paeen" (literally means "the girls from below", which refers to gay individuals from the south of Tehran or generally from the lower social class).

Participant 4

There is less of a likelihood that working-class men will describe themselves as gay or be members of a socially visible gay culture (Barrett and Pollack 2005). The decreased probability of openly admitting to being gay, the length of time between commencing same-sex relationships and coming out to others, and the high probability of having sexual relations with women despite a lack of desire to do so are all indicative that the standards of masculinity related to social class have a controlling effect on the social lives of working-class gay men (Barrett and Pollack 2005). Class factors related to intimate relationship stability also appear to play a role in the lower likelihood of being involved in a primary relationship. 


\section{Developing a New Identity (Using a Nickname)}

Thirteen participants mentioned that they used a nickname when they were with other gay individuals. They indicated that this was very common practice, primarily as a means of protecting themselves and not being recognised by other people. As mentioned by participant 16, who was 21 years old, single, and a student:

...You shouldn't let other gays know about your family and even where you live. It would give others a power over you which then would put you in a vulnerable position ... they could potentially blackmail you especially if they hold a grudge against you.

Participant 16

In addition, it has been reported that "the threat of blackmail is now a huge problem for gay men" in Iran (Banning-Lover 2017). Another reason mentioned for using an alias was that creating a new identity created a sense of freedom. By creating their own identity, they could be the person they wanted to be. For instance, participant 19, who was 22 years old, single and dating, and a student, said:

...if you are not sociable when you are with your family or at work, when you are with your gay friends, you have your own name and personality...

Participant 19

Studies of sexual minorities indicate that the development of the gay individual's identity tends to be unique as a result of their particular experiences of prejudice and social oppression (Diamond et al. 2012). While some studies have shown a degree of inconsistency in this development of an identity, there remains uncertainty over the specific individual or social contexts that determine these variable pathways towards identity integration (Rosario et al. 2011). One of the more popularly accepted influences seems to be the concept of experience, which includes oppression in the form of minority stress. For example, it is known that acts of prejudice and/or discrimination impact the sense of self in other minority populations as suggested by Atkinson et al. (1995). Moreover, prejudice and discrimination can have a permanent effect on an individual's sense of self, regardless of whether such acts were experienced directly by the individual or observed indirectly in others. Researchers studying minority stress have hypothesised that it is chronic, socially-based, and unique, as well as being additional to the general stressors that everyone experiences (Meyer 2003). Despite the widespread agreement on the importance of these and other experiences in the development of a sexual minority identity, such experiences alone cannot explain all of the variances that occur. If this were the case, then each individual who is exposed to the same or similar experiences would develop the same identity, but this is not the case. The interpretive process of each individual is a major factor in determining the extent to which a stressful event or experience influences their identity development (Rosario et al. 2011). 


\section{Limitations}

There are a number of limitations related to this study. The data in this study were based on interviews which relied on the participants' narratives, therefore leaving a possibility of bias, particularly with regard to sensitive subjects, such as sexual relationships.

In thematic analysis, one of the main issues is that when the codes are separated from their context, it results in a distortion of the overall picture, which can be resolved to some extent by adopting a more person-centred approach (e.g. Thagaard 2003). Despite these suggestions, it is the opinion of the researcher that a purely thematic approach constitutes the most appropriate method of analysis in the present study on the reasoning that the gay community in Iran is a small and vulnerable group and, therefore, the person-centred approach could compromise the participants' anonymity. Moreover, as the qualitative research is highly subjective and the researcher's personality and experience might affect the validity and reliability of the research (Creswell 2014), it is important to mention that the researcher is fully aware of his own possible biases and preconceptions due to his few years of practice as a psychological therapist with LGBT individuals and LGBT organisations as well as his previous research experience in this field, especially among gay men and male-to-female transgender individuals. However, the researcher believes that his awareness of his own biases helped him to prevent any influence on his judgment, the coding process, or the conclusions drawn. Furthermore, in this study, the participants were not aware of the sexual orientation of the researcher. As a result, answering questions about sex and sexual behaviour would likely have been awkward and somewhat formal. In other words, they were likely to have felt 'forced' to answer questions about what is a sensitive subject, and thus used terminology that they would not normally use in less formal settings, such as when talking with friends or partners. This creates a limitation for the study as the answers would not be entirely natural and lacking in openness and spontaneity.

\section{Conclusion}

Throughout the 40 years (1979-2019) of oppression under Iran's Islamic law, during which social rules and laws have been designed to prevent gay males living in Iran from being open about their sexuality, many gay males living in Iran have actively sought to overcome these restrictions on their freedom. The structure of Iran's gay population has become more complex when we consider that certain individuals can find themselves changing their social identity several times a day as they move from one social community to the next through the course of their daily activities. Fulfilling multiple social roles, enacting various social norms, and guided by diverse expectations, they alternate regularly between one social group and another. In such a situation of constant flux and change, anxiety can easily develop, especially for those whose roles are not well coordinated and whose relationships are not systematically organised. In such an environment of persecution, gay men in Iran have developed their own survival techniques. Gay individuals have found ways of 
communicating with each other and over time they have created their own underground gay community. It is hardly surprising in such an oppressive and secretive environment of institutionalised discrimination that the members of Iran's underground gay community experience emotions of fear, anger, rejection, and frustration, leading them to develop a variety of coping strategies. Originally developed as survival techniques, these coping strategies have become, over time, part of what we know today as "gay culture" and it seems that one of its more effective benefits has been in providing the coordination and organisation that enable its members to maintain a sense of order in their lives as they navigate from one social situation to the next, minimising anxiety as a result. The gay culture in Iran achieves this by creating an information-sharing system that its members can access via their specific gay communities. Shared not only among gay communities but also across generations, this information-sharing system empowers members of the Iranian gay culture to overcome both physical and psychological hurdles by giving them a sense of belonging, the freedom to pursue happiness and well-being, and genuine meaning in their lives.

\section{Compliance with Ethical Standards}

Conflict of interest The author declares that he has no conflict of interest.

Ethical Approval All procedures performed in studies involving human participants were in accordance with the ethical standards of the national research committee and with the 1964 Helsinki declaration and its later amendments or comparable ethical standards.

Informed Consent Informed consent was obtained from all individual participants included in the study.

Open Access This article is distributed under the terms of the Creative Commons Attribution 4.0 International License (http://creativecommons.org/licenses/by/4.0/), which permits unrestricted use, distribution, and reproduction in any medium, provided you give appropriate credit to the original author(s) and the source, provide a link to the Creative Commons license, and indicate if changes were made.

\section{References}

Amin, S. (2015). Gender X: A glance at the situation of transgender \& homosexual people in Iran. Retrieved 2018, from http://6rang.org/: http://6rang.org/wp-content/uploads/2015/12/Jensiat-X.pdf.

Atkinson, D. R., Morten, G., \& Sue, D. W. (Eds.). (1995). Counselling American minorities: A cross cultural perspective (5th ed.). Dubuque, IA: William C. Brown.

Banning-Lover, R. (2017). Where are the most difficult places in the world to be gay or transgender? Retrieved 2018, from www.theguardian.com, https://www.theguardian.com/global-developmen t-professionals-network/2017/mar/01/where-are-the-most-difficult-places-in-the-world-to-be-gayor-transgender-lgbt.

Barrett, D. C., \& Pollack, L. M. (2005). Whose gay community? Social class, sexual self-expression, and gay community involvement. The Sociological Quarterly, 46, 437-456.

BBC News. (2017). Iran's morality police storm solstice parties to arrest 230 people. Retrieved 2018, from www.bbc.co.uk, https://www.bbc.co.uk/news/world-middle-east-42459544.

BBC News. (2018). Contaminated bootleg alcohol kills at least 42 in Iran. Retrieved 2018, from www. bbc.co.uk, https://www.bbc.co.uk/news/world-middle-east-45709203. 
Bowman, K. H. (2004). Attitudes about homosexuality and gay marriage: AEI studies in public opinion. American Enterprise Institute. Retrieved 2018, from http://www.aei.org/publications/pubID.14882 ,filter./pub_detail.asp.

Braun, V., \& Clarke, V. (2013). Successful qualitative research: A practical guide for beginners. London: Sage.

British Psychological Society. (2014). Code of human research ethics. Leicester: BPS.

Brooks, V. R. (1981). Minority stress and lesbian women. Lexington, MA: Heath.

Butler, J. (2002). Antigone's claim: Is kinship always already heterosexual? Lecture at University of Southern Stockholm, Sweden, 27 April.

Choudhury, S. M., Erausquin, J. T., Park, K., \& Anglade, D. (2015). Social support and sexual risk among establishment-based female sex workers in Tijuana. Qualitative Health Research, 25, 1056-1068.

Cohanzad, S. (2012). Interview with a practitioner who has done 152 sex reassignment surgeries so far. Retrieved 2018, from http://www.iranianuk.com/page.php5?id=20121109125013019.

Creswell, J. W. (2014). Research design: Qualitative, quantitative, and mixed methods approaches (4th ed.). CA: Sage.

Crossley, M. L. (2004). Making sense of barebacking: Gay men's narratives, unsafe sex and the resistance habitus. British Journal of Social Psychology, 43, 224-225.

David, E. J., \& Dethrick, A. O. (2014). What is internalized oppression and so what? In E. R. David (Ed.), Internalized oppression: The psychology of marginalized groups (pp. 1-30). New York: Springer.

Davies, D., \& Neal, C. (2003). A historical overview of homosexuality and therapy. In D. Davies \& C. Neal (Eds.), Pink therapy, a guide for counsellors and therapist working with lesbian, gay and bisexual clients (pp. 11-23). Maidenhead: Open University Press.

Dehlin, J. P. (2015). Sexual orientation change efforts, identity conflict, and psychosocial health amongst same-sex attracted mormons. Utah: Utah State University. Retrieved 2018, from https://digitalcom mons.usu.edu/cgi/viewcontent.cgi? article $=5314 \&$ context $=$ etd.

Diamond, L. M., Butterworth, M. R., \& Allen, K. (2012). Sexual-minority development in the family context. In P. K. Kerig, M. S. Schulz, \& S. T. Hauser (Eds.), Adolescence and beyond: Family processes and development (pp. 249-267). Oxford: Oxford University Press.

Farley, J. E., \& Flota, M. W. (2017). Sociology. London: Taylor and Francis.

Forbes, S. (2017). The reconstruction of homosexuality and its consequences in contemporary Iran. The SOAS Journal of Postgraduate Research, 10, 25-47.

Giddens, A., \& Griffiths, S. (2006). Sociology (5th ed.). Cambridge: Polity Press.

Giddens, A., \& Sutton, P. W. (2017). Sociology. Cambridge: Polity Press.

Glick, S. N., \& Golden, M. R. (2014). Early male partnership patterns, social support, and sexual risk behavior among young men who have sex with men. AIDS Behaviour, 18, 1466-1475.

Golkar, S. (2010). The ideological-political training of Iran's Basij, No. 44. Crown Center for Middle East Studies. Retrieved 2018, from https:/www.scribd.com/document/38315692/The-Ideologica 1-Political-Training-of-Iran-s-Basij.

Greene, B. (2010). Delivering ethical psychological services to lesbian, gay and bisexual clients. In K. J. Bieschke, R. M. Perez, \& K. A. DeBord (Eds.), Handbook of counseling and psychotherapy with lesbian, gay, bisexual and transgender (2nd ed., pp. 181-199). Washington: American Psychological Association.

Hamedani, A. (2014). The gay people pushed to change their gender. Retrieved 2018, from www.bbc. co.uk, https://www.bbc.co.uk/news/magazine-29832690.

Hollway, W., \& Jefferson, T. (2013). Doing qualitative research differently: A psychosocial approach (2nd ed.). London: Sage.

Homosexuality iii. (2012). In Persian literature. In Encyclopedia Iranica. Retrieved 2018, from http:// www.iranicaonline.org/articles/homosexuality-iii.

Human Rights Watch. (2010). Iran: Discrimination and violence against sexual minorities. Retrieved 2018, from www.hrw.org, https://www.hrw.org/news/2010/12/15/iran-discrimination-and-violenceagainst-sexual-minorities.

Ikrami, H. (2013). The violations of the economic, social, and cultural rights of lesbian, gay, bisexual, and transgender (LGBT) persons in the Islamic Republic of Iran. Retrieved 2018, from http://hrp. law.harvard.edu/, http://hrp.law.harvard.edu/wp-content/uploads/2011/01/JointHeartlandAlliance_ IRQO_IHRC_Iran_CESCR50.pdf.

Iran: Islamic Penal Code. (1991). Islamic Penal Code as of 1991. Retrieved 2018, from http://www.refwo rld.org, http://www.refworld.org/docid/518a19404.htm. 
Janghorban, R., Latifnejad Roudsari, R., \& Taghipour, A. (2014). Skype interviewing: The new generation of online synchronous interview in qualitative research. International Journal of Qualitative Studies on Health and Well-Being, 9, 24152. https://doi.org/10.3402/qhw.v9.24152.

Johanston, L., Steinhaus, M., Sass, J., Benjarattanaporn, P., Sirinirund, P., Siraprapasiri, T., et al. (2017). The associations of perceived social support with key HIV risk and protective factors among young males who have sex with males in Bangkok and Chiang Mai, Thailand. AIDS and Behaviour, 22, $1-9$.

Justice for Iran. (2014). Diagnosing Identities, wonding bodies: Medical abuse and other human rights violation against lesbian, gay, and transgender people in Iran. Retrieved 2018, from Justice4iran. org: https://justice4iran.org/wp-content/uploads/2014/06/Pathologizing-Identities-Paralyzing-Bodie s.pdf.

Kapadia, F., Siconolfi, D. F., Barton, S., Olivieri, B., Lombardo, L., \& Halkitis, P. N. (2013). Social support network characteristics and sexual risk taking among a racially/ethnically diverse sample of young, urban men who have sex with men. AIDS Behaviour, 17, 1819-1828.

Karimi, A. (2016). Iranian homosexuals; social identity formation and question of femininity. Culture \& Psychology, 22, 296-313.

Khosravi, Shahram. (2009). Displaced masculinity: Gender and ethnicity among Iranian men in Sweden. Iranian Studies, 42, 591-609.

Levi-Strauss, C. (1969). The elementary structures of kinship (2nd ed.). Boston: Beacon Press.

Mahdavi, P. (2012). Questioning the global gays(ze): Constructions of sexual identities in post-revolution Iran. Social Identities: Journal for the Study of Race, Nation and Culture, 2, 223-237.

Majumdar, D. (2006). Social support and risky sexual behavior among adolescents: The protective role of parents and best friends. Journal of Applied Social Science, 23, 28-43.

Manalansan, M. (2006). Queer intersections: Sexuality and gender in migration studies. The International Migration Review, 40, 224-249.

Marchant, J. (2018). Breaking the Silence digital media and the struggle for LGBTQ rights in Iran. Retrieved 2018, from www.smallmedia.org.uk, https://smallmedia.org.uk/media/projects/files/Break ingTheSilence_2018.pdf.

Mason, M. (1990). Internalized oppression. In R. Reiser \& M. Mason (Eds.), Disability equality in education. London: Inner London Education.

Matsumoto, D., \& Juang, L. (2017). Culture and psychology (6th ed.). Boston, MA: CENGAGE Learning.

Merriam, S. B., \& Tisdell, E. J. (2016). Qualitative research: A guide to design and implementation (4th ed.). San Francisco: Jossey-Bass.

Meyer, I. H. (2003). Prejudice, social stress, and mental health in lesbian, gay, and bisexual populations: Conceptual issues and research evidence. Psychological Bulletin, 129, 674-697.

Nehls, K., Smith, B. D., \& Schneider, H. A. (2015). Video-conferencing interviews in qualitative research. In S. Hai-Jew (Ed.), Enhancing qualitative and mixed methods research with technology (pp. 140-157). Hershey PA: Information Science Reference.

NHS. (2014). Mental health issues if you're gay, lesbian or bisexual. UK: NHS. Retrieved 2018, from http://www.nhs.uk/Livewell/LGBhealth/Pages/Mentalhealth.aspx.

Parnian, H. (2006). The sexual rights of women and homosexuals in Iran. In S. Seidman, N. Fischer, \& C. Meeks (Eds.), Handbook of the new sexuality studies (pp. 348-352). New York, NY: Routledge.

Rosario, M., Schrimshaw, E. W., \& Hunter, J. (2011). Different patterns of sexual identity development over time: Implications for the psychological adjustment of lesbian, gay, and bisexual youths. Journal of Sex Research, 48, 3-15.

Saastamoinen, A. (2017). Iranian queer refugees' thoughts about home five queer/gay men interviewed about their sense of belonging after emigration. Retrieved 2018, from http://epublications.uef.fi, http://epublications.uef.fi/pub/urn_nbn_fi_uef-20170568/urn_nbn_fi_uef-20170568.pdf.

Saleh, L. D., van den Berg, J. J., Chambers, C. S., \& Operario, D. (2016). Social support, psychological vulnerability, and HIV risk among African American men who have sex with men. Psychology and Health, 31, 549-564.

Shamisa, S. (2002). Shahedbazi dar Adabiat Iran [Sodomy: based on Persian literature]. Tehran: Ferdows.

Simons, H., \& Usher, R. (2000). Introduction: Ethics in the practice of research. In H. Simons \& R. Usher (Eds.), Situated ethics in educational research (pp. 1-11). London: Routledge Falmer.

Taylor, B. J. (2017). Heuristics in professional judgement: A psycho-social rationality model. British Journal of Social Work, 47, 1043-1060. 
Thagaard, T. (2003). Systematikk og innlevelse: en innføring i kvalitativ metode. Bergen: Fagbokforl.

Tracy, S. J. (2010). Qualitative quality: Eight "Big-Tent" criteria for excellent qualitative research. Qualitative Inquiry, 16, 837-851.

UK Home Office. (2016). Country information and guidance Iran: Sexual orientation and gender identity. Retrieved 2018, from www.gov.uk, https://assets.publishing.service.gov.uk/government/uploa ds/system/uploads/attachment_data/file/565824/CIG-Iran-SOGI-v2-September-2016.pdf.

van Nes, F., Abma, T., Jonsson, H., \& Deeg, D. (2010). Language differences in qualitative research: Is meaning lost in translation? European Journal of Ageing, 7, 313-316.

Varney, J. (2016). Improving the mental health and wellbeing of lesbian, gay, bisexual and trans individuals. Retrieved 2018, from publichealthmatters.blog.gov: https://publichealthmatters.blog.gov. uk/2016/05/19/improving-the-mental-health-and-wellbeing-of-lesbian-gay-bisexual-and-trans-indiv iduals.

Warr, D. (2004). Stories in the flesh and voices in the head: Reflections on the context and impact of research with disadvantaged populations. Qualitative Health Research, 14, 578-587.

Weston, K. (1997). Families we choose: Lesbians, gays, kinship. New York: Columbia University Press.

Whitcomb, D. H., \& Walinsky, D. J. (2013). Lesbian, gay, and bisexual issues, social class, and counseling. New York: Oxford University Press.

Wolitski, R., Stall, R., \& Validiserri, R. (2008). Unequal opportunity: Health disparities affecting gay and bisexual men in the United States. New York: Oxford University Press.

World Health Organization. (2014). Alcohol consumption: Levels and patterns, Iran (Islamic Republic of). Retrieved 2018, from WWW.who.int, http://www.who.int/substance_abuse/publications/globa 1_alcohol_report/profiles/irn.pdf.

Yadegarfard, M., \& Bahramabadian, F. (2014). Sexual orientation and human rights in the ethics code of the psychology and counseling organization of the Islamic Republic of Iran (PCOIRI). Ethic \& Behaviour, 24, 350-363.

Yadegarfard, M., Bahramabadian, F., \& Ho, R. (2015). Iranian psychotherapists' behaviors and beliefs toward sexual orientation and gender identity. Ethics and Behavior, 25, 256-270.

Yadegarfard, M., Meinhold-Bergmann, M., \& Ho, R. (2014). Family rejection, social isolation, and loneliness as predictors of negative health outcomes (depression, suicidal ideation and sexual risk behaviour) among Thai male-to-female transgender adolescents. Journal of LGBT Youth, 11, 347-363.

Yasami, M. T., Mohammadi, A., Kameli, J., Usofi, M. R., \& Samimi Ardestani, M. (2007). Successful treatment experiences of homosexuality, paraphilia and transsexuality by cognitive-behaviour therapy. Forensics, 12, 222-227.

Zarghami, M. (2015). Iranian common attitude toward opium consumption. Iranian Journal of Psychiatry and Behavioural Sciences, 9, e2074.

Publisher's Note Springer Nature remains neutral with regard to jurisdictional claims in published maps and institutional affiliations. 